\title{
Perceptions of the Clinical Competence of New Speech-Language Pathology Graduates in New Zealand: A Research Note
}

\author{
Gina Tillard*, Kim Lawson and Shannon Emmerson \\ Department of Communication Disorders, University of Christchurch, Private Bag 4800, Ilam, Christchurch 8410, New \\ Zealand
}

\begin{abstract}
Background: This study arose as the Course Leader sought feedback on the adequacy of the programme to prepare new graduates for professional practice.

Aims: The aim was to examine how well an undergraduate degree programme prepared speech pathology graduates for the workforce, focussing on a range of core competencies including theoretical knowledge, clinical skills and professionalism.
\end{abstract}

Methods \& Procedures: Thirty new graduates and 30 employers were approached to participate in the study, with 19 and 16 accepting respectively. A written survey of 15 questions, 11 of which employed a Likert 5-point scale, and four of which were open-ended requiring a short written answer. Of the 11 rateable questions, nine were directed at both graduates and employers and the remaining three were directed at either group. Results were subjected to non-parametric between group comparisons. Open-ended questions were scanned for themes.

Outcomes and Results: Employers and graduates did not differ on their perception of new graduate competence across all skill areas except writing skills. The employers rated the new graduates significantly lower on writing skills than did graduates. Both employers and graduates believed they were well-prepared for professional practice. Emerging themes in the open-ended questions were the continuity of location of clinical placements and employment, professional development, professional support, integration of academic and clinical education, and specific topic areas of strengths and weaknesses in the undergraduate curriculum.

Conclusions: The study provides insight as to the preparedness of new SLP graduates upon entering the workforce. Considering the views of both the new graduate and employer are vital if university programmes are to address the expanding scope of practice in the field of communication sciences and disorders.

Keywords: Clinical education, employer expectations, speech-language pathology, survey.

\section{INTRODUCTION}

The overall aim of clinical education in the field of communication sciences and disorders is to facilitate learning and develop student clinicians who are both professional and clinically competent. Rapidly-changing workplaces combined with a variety of possible employment contexts provide a great challenge for the clinical education of students. The difficulty of catering for an evolving and widening role within the workplace is one factor which influences the clinical education of speech-language pathologists (SLP) [1].

There have been a handful of studies exploring the issue of graduate competence in a range of workplaces [1-3]. For example, Anderson [3] found SLP graduates felt that they had a lack of experience in research, a need for continued education, and lack of ability in caseload management. The same study found that less than half of the final-year students surveyed $(n=29)$ felt they had sufficient knowledge for practice but over half felt they were competent for practice

*Address correspondence to this author at the Department of Communication Disorders, University of Christchurch, Private Bag 4800, Ilam, Christchurch 8410, New Zealand; Tel: (64 3) 3642 497; Fax: (64 3) 3642 760; E-mail: gina.tillard@canterbury.ac.nz (i.e., possessed the basic skills). Quality of supervision of new graduates and protected client non-contact time were highlighted as two major factors in determining graduates' self-perceived levels of competence [3]. In a study of allied health graduates in Australia, Adamson et al. [2] found generic undergraduate training weaknesses around the issues of workplace management, knowledge of the health industry, coping in the workplace, and communication skills. More than one quarter of graduates felt inadequately prepared for practice. A follow-up report by Harris et al. [4] reported improved preparedness ratings following revised curriculum implementation targeting communication skills and professional development issues.

An important issue in the clinical education of SLP students is to validate whether they are professionally and clinically competent once entering the workforce. Yet, there is limited research examining how well university programmes prepare SLP graduates for the workforce. University programmes need to know if employers and graduates believe they are adequately prepared. The purpose of the current study was to determine how well one university clinical education programme in New Zealand was preparing students for employment. This was achieved by soliciting employer assessments of the performance level 
of new graduates, and new graduate impressions of their university preparation against actual requirements as a clinician in the workplace.

\section{METHOD}

\section{Participants}

A cohort of new graduates and their employers were included in the survey. The graduates had completed a fouryear undergraduate Bachelor's degree at the University of Canterbury (Christchurch, New Zealand). The Bachelor's degree is the requisite qualification for practicing as a SLP in New Zealand, Australia, and the United Kingdom. The study received approval from the ethics committee of the University of Canterbury. Surveys were mailed to 30 employers and new graduates approximately three months following the commencement of employment.

\section{Survey Instrument}

A survey instrument containing 15 items was developed, including 11 answered by a 5-point rating scale and four requiring short answers (see Appendix). The items represented skill areas which were derived from review of speech-language pathology competency assessment of students used at the University of Canterbury and cross referenced to generic speech-language pathology position descriptions. Employers and new graduates were required to provide ratings for the graduate's skill levels or preparation for employment respectively, across eight common skill areas. In addition, the employees and new graduates were required to assign an overall performance rating. Separate ratings were given for independence level (employers) and contractual issues (new graduates). Operational definitions were provided for the ratings and no operational definitions were provided for the skill areas. Short answer questions were tailored around professional support and development, and perceived areas for improvement in the University programme. These were anticipated to be areas closely linked to effective application of skills taught as a student, and therefore perceived degree of competence.

\section{Statistical Analysis}

Results were based on an average of the 5-point scale values reported by employers and employees. A mean rating was established for each skill area. These means were collated and submitted to statistical analyses. A series of Mann-Whitney Rank Sum Tests (one-tailed) were used to determine whether there was a statistically significant difference between employer and graduate groups across the eight common areas and overall ratings.

\section{RESULTS}

Of the 30 surveys sent to the graduates and their employers, 19 graduates (63\%) and 16 employers $(53 \%)$ responded. In some instances, an employer had more than one graduate. In these cases the employer filled out a separate survey for each graduate. Of the 19 graduates who responded, 14 graduates $(73 \%)$ were employed by the Ministry of Education and 5 graduates (26\%) were employed by District Health Boards. Of the 16 employers who responded, nine $(56 \%)$ were reporting on graduates in the Ministry of Education and seven employers (44\%) were reporting on graduates in the District Health Boards.
The results are presented in two sections. The first section contains the results from the Graduate/Employer comparison related to the 11 questions requiring rating on a 5 -point scale. The second section contains a summary of the four questions requiring a short answer response. The results of the short answer questions were summarised and organised according to general themes.

\section{The Graduate/Employer Comparison}

The results of the survey and related statistical analyses are listed in Table 1. The graduates' overall performance was found to meet expectations of employers (rating higher than 3 ) in $87 \%$ (12 out of 16) of cases. No significant difference was found between graduate and employer responses on the rating of the various skill areas with the exception of writing ability. Employers ranked graduates significantly lower on writing ability $(U=82, p=.04)$. In general, the mean ranks for employers were slightly higher than graduates' selfratings on caseload management, teamwork, and theoretical knowledge. Graduates rated themselves slightly higher than did employers on their overall performance, relevant clinical experience at an undergraduate level, writing ability, assessment and therapy skills, and professionalism.

\section{Short Answer Summary}

Work Independence. In relation to independence, both graduates and employers stated that the ideal scenario was for students to move from their final clinical placement into employment within the same workplace. In these cases, both groups reported an immediate ability for the graduate to work independently as a practitioner. Otherwise, there was great variation in reported length of time required before a new graduate was able to operate independently (anywhere from 1 to 6 months). Generally, graduates finding employment in a health context required longer adaptation periods within rehabilitation than acute settings. For graduates working in educational settings, the major obstacle preventing a seamless entry into independent practice appeared to be the lack of experience in working with complex cases.

Professional Development. The professional development offered to new graduates by their employers had a similarly wide range. While some graduates reported having no formal professional development other than what was self-directed, others described effective and thorough new graduate induction and development packages. Preferred methods of professional development included (a) shadowing experienced clinicians within specialist areas, (b) personal goal setting and reviews, and (c) reflective practice facilitated in regular supervision. Supervision was offered by the great majority of employers surveyed, and had only been ineffective in one case. Graduates preferred formal arrangements for professional development, and these appeared to be more effective and less likely to be replaced by caseload issues.

Professional Support. Professional support commonly consisted of less formal arrangements, such as peer review, case discussion and debriefing opportunities. To have these available on a needs basis was helpful to graduates as a whole. Graduates did not generally expect support from the university faculty, other than as a resource for contacts with 
classmates and specialist areas where managers were unable to help.

University Programme. In terms of areas for improvement in the university programme, there was encouragement for the university faculty and clinical field supervisors to have closer contact in order to increase the relevance of clinical training. Equally, graduates commented on the need for the academic and clinical components of the programme to be well integrated. Imbalances in the academic programme noted by both employers and graduates were too much emphasis on (a) assessment rather than therapy, (b) phonology and phonological awareness rather than language and classroom intervention, (c) academic skills at the expense of clinical skills, and (d) dysphagia rather than aphasia. Areas of service delivery that were viewed as weaknesses for the University included: voice therapy, augmentative and alternative communication, tracheostomy and laryngectomy management, cognitive neuropsychology, functional assessment, pre-verbal communication, high-needs children, and fluency. Clinical management issues identified as requiring more focus were caseload and prioritisation, time management, understanding and utilising the multidisciplinary team and/or volunteers to provide collaborative service delivery, and planning appropriate management following assessment. Many supervisors believed that longer clinical placements in the field coupled with allowing more opportunity for independent caseload management within the final placement, would be of benefit. Some respondents expanded on this idea and suggested an intern year. However, the greatest request was that on-campus university clinics should better reflect real work situations.

\section{DISCUSSION}

The results of the present study should be considered preliminary. The sample size was small and reflected a response rate of approximately $60 \%$. Still, the findings of the survey were encouraging for the university faculty, with the programme producing students who were well-prepared and meeting expectations for employment. There was one statistically significant finding in the study. Employers rated graduates lower on writing skills compared to how graduates rated themselves. A possible explanation for this is the ability to transfer academic writing style to patient documentation. In addition, employers and graduates may have been reporting on different aspects of writing skills. For example, new graduates may spend a disproportionate amount of time completing documentation while the quality may be satisfactory. A related example can be found in the work of Oxentenko et al. [5] which reported that internal medicine residents spent almost as long completing documentation as they spent seeing patients.

Overall perception of preparedness for the workplace far exceeded those in other studies [2, 3]. Dysphagia was recognized as a significant strength in the teaching programme, which may have been reflected in claimed greater independence levels of graduates in acute versus rehabilitation settings. Graduates working in education reported a lack experience in working with complex cases. These cases are generally managed in the school system rather than being referred to the university clinic. So the lack of experience is perhaps not surprising. These issues, as well as the responses to the questions answered only by the employers suggest the need for an accelerated programme of allowing final-year students to take more responsibility for complex cases and greater client numbers at an earlier stage in their final year of supervised practicum experience. Clearly, this final clinical experience is critical, both in terms of placement of students in settings where they may potentially be employed (either specific workplace or general context), and in allowing the student to take full caseload responsibility and thus gain essential management and prioritisation skills and a realistic expectation of workload. These weaknesses are compatible with those found by Adamson et al. [2]. Graduates of the University of Canterbury programme reported having excellent skills in this area, apart from terminal care counselling, which is acquired largely with experience.

The aim of any clinical programme is to provide a wide range of clients and disorders to the student. In reality, this is often not entirely possible given a small population base. The profession in New Zealand is also experiencing the emergence of many specialist areas and expansion of service delivery into new fields. Thus, the onus is upon training programmes to be diligent in remaining up-to-date with

Table 1. Mean Rank, N and Mann-Whitney U Comparison for Graduates and Employers on Eight Competence Variables

\begin{tabular}{|c|c|c|c|c|c|}
\hline \multirow{2}{*}{ Variable } & \multicolumn{2}{|c|}{ Graduates } & \multicolumn{2}{|c|}{ Employers } & \multirow{2}{*}{ Mann-Whitney $\boldsymbol{U}(\boldsymbol{p})$} \\
\cline { 2 - 5 } & Mean Rank & $\mathbf{N}$ & Mean Rank & N & 16 \\
\hline \hline Overall performance & 17.26 & 19 & 18.88 & 16 & $138.0(.67)$ \\
\hline Clinical experience & 17.61 & 19 & 18.47 & $144.5(.81)$ \\
\hline Caseload management & 16.45 & 19 & 19.84 & 16 & $122.5(.33)$ \\
\hline Teamwork & 16.28 & 18 & 18.88 & 16 & $122.0(.46)$ \\
\hline Theory & 16.28 & 18 & 18.88 & 16 & $122.0(.46)$ \\
\hline Writing & 20.68 & 19 & 13.47 & 15 & $82.0(.04)$ \\
\hline Assessment & 19.53 & 19 & 16.19 & 15 & $123.0(.35)$ \\
\hline Therapy & 16.19 & 18 & 17.97 & 15 & $120.5(.61)$ \\
\hline Professionalism & 20.55 & 19 & 14.97 & 16 & $103.5(.11)$ \\
\hline
\end{tabular}


current practice and evaluate what material is critical for training on an ongoing basis. Similar conclusions were made by Brumfitt et al. [1] and Higgs and Hunt [6]. Many of the areas identified as weaknesses by new graduates and employers alike were linked to specialist areas of the profession and highlight the small client base available for exposure to students during their training. The university is currently investigating alternative methods of delivering the curriculum delivery, including videoed therapy sessions, simulated cases, and better integration of academic and clinical instruction via more use of case-based learning.

Professional development, particularly reflective practice, has been previously described as a critical role of clinical educators and a lifelong skill to promote selfdirected learning in a changing work environment $[3,7]$. The present study also found professional development to be a key part of the solution to most issues. This finding is not unique as several other studies have reported that ongoing professional development and release for uptake of training opportunities were vital for maintaining and updating knowledge of practice issues and procedures, as well as for maintaining confidence in one's own professional abilities $[8,9]$. The university has introduced a reflective practice component into the student's final clinical practicum experience that focuses on inter-professional learning and teamwork. It was envisaged that this initiative would address at least three target areas, (1) team work, (2) reflective practice and (3) personal goal-setting and review [10].

Of major concern was the number of respondents who commented that negotiated release time for professional development purposes was being "lost due to caseload" and "put to the bottom of the pile of things that have to be done". However, findings show that formalising professional support greatly reduced the likelihood of negotiated professional development time being consumed by caseload issues. Anderson [3] also stressed the need for graduates to be well supported, given that no training can fully prepare them for autonomous practice. She suggested this support be structured, consistent and protected.

In conclusion, generalisations from the findings of the study are limited by the small sample size. However, the results of the study provide insight as to the preparedness of new SLP graduates upon entering the workforce. Considering the views of both the new graduate and employer are vital if university programmes are to address the expanding scope of practice in the field of communication sciences and disorders. Future research could expand the use of the survey tool established for this study. It may be beneficial to consider further developing the tool to establish the impact of curriculum changes and revision of clinical education practices on the perceptions of clinical competence of graduates, thus establishing a cycle of review.

\section{ACKNOWLEDGEMENTS}

The authors wish to thank and acknowledge the participation of both the graduating speech-language pathology students and their employers in this study.

\section{CONFLICT OF INTEREST}

None declared.

\section{APPENDIX}

Survey completed by new graduates and employers of new graduates

Name (optional)

Setting (circle) Public health Private health Education Other Position

Duration of graduate's employment

\section{Section A. Rating Questions}

Please rate the graduate's skills in the following areas when they first came to work by ticking the appropriate column using the rating scale below:

$1=$ Well below expected level (for a new graduate)

$2=$ Below expected level (for a new graduate)

$3=$ Met expected level (for a new graduate)

$4=$ Above expected level (for a new graduate)

$5=$ Well above expected level (for a new graduate)

\begin{tabular}{|l|l|l|l|l|l|l|}
\hline \multicolumn{1}{|c|}{ Skill Area } & $\mathbf{1}$ & $\mathbf{2}$ & $\mathbf{3}$ & $\mathbf{4}$ & $\mathbf{5}$ & Comments \\
\hline \hline 1. Professionalism & & & & & & \\
\hline $\begin{array}{l}\text { 2. } \\
\text { Relevant university clinical } \\
\text { experience }\end{array}$ & & & & & & \\
\hline 3. $\quad$ Relevant academic preparation & & & & & & \\
\hline 4. $\quad$ Caseload management & & & & & & \\
\hline 5. $\quad$ Teamwork & & & & & & \\
\hline 6. Clinical writing & & & & & & \\
\hline 7. Assessment & & & & & & \\
\hline 8. Therapy & & & & & & \\
\hline 9. Independence level & & & & & & \\
\hline 10. Relationship management & & & & & & \\
\hline 11. Overall performance & & & & & & \\
\hline
\end{tabular}

Section B. Short Answer Responses

1. In your opinion, how long did it take before you (or your new graduate employee) was operating independently?

2. What type and degree of professional development do you currently receive (or offer to your new graduate employee)?

3. What type and degree of professional support do you currently receive (or provide to your new graduate employee)?

4. How do you believe the University of Canterbury programme could most improve the clinical performance of future graduates?

\section{REFERENCES}

[1] Brumfitt S, Hoben K, Enderby P, Goddard V. Informing educational change to improve clinical competence. Int J Lang Commun Disord 2001; (Suppl 36): 406-10. 
[2] Adamson BJ, Harris LM, Hunt AE. Health science graduates: Preparation for the workplace. J Allied Health 1997; 26: 187-99.

[3] Anderson H. Clinical teaching and mentoring: Vital in the development of competent therapists. Int J Lang Commun Disord 2001; (Suppl 36): 138-43.

[4] Harris LM, Adamson BJ, Reed V, Hunt AE. Impact of curricular change in an undergraduate program for speech pathologists on perceived preparedness for the workplace. J Allied Health 1998; 27: 221-7.

[5] Oxentenko AS, West CP, Popkave C, Weinburger SC, Kolars JC. Time spent on clinical documentation: a survey of internal medicine residents and program directors. Arch Intern Med 2010; 170 (4): $337-80$.
[6] Higgs J, Hunt A. Preparing for the workplace: Fostering generic attributes in allied health education programs. J Allied Health 1999; 28: 230-9.

[7] Baxter S, Gray C. The application of student-centred learning approaches to clinical education. Int J Lang Commun Disord 2001; (Suppl 36): 396-400.

[8] Ward E, Agius E, Solley M, Cornwell P, Jones C. Preparation, clinical support, and confidence of speech-language pathologists managing clients with a tracheostomy in Australia. Am J Speech Lang Pathol 2008; 17: 265-37.

[9] Campbell PH, Chiarello L, Wilcox MJ, Milbourne S. Preparing therapists as effective practitioners in early intervention. Infants Young Child 2009; 22: 21-31.

[10] Ormond T. Student perceptions of Inter-professional Learning in a health profession. (Submitted).

This is an open access article licensed under the terms of the Creative Commons Attribution Non-Commercial License (http: //creativecommons.org/licenses/by$\mathrm{nc} / 3.0 /$ ) which permits unrestricted, non-commercial use, distribution and reproduction in any medium, provided the work is properly cited. 